\title{
PERAN PESERTA DIDIK SMA NEGERI 2 PADANG PANJANG DALAM MEMBANGUN JIWA WIRAUSAHA MELALUI MEDIA ONLINE PADA MASA PANDEMI COVID-19
}

\author{
Eliza $^{1}$, dan Jumiatul Mulya ${ }^{2}$ \\ 'Program Studi Akuntansi, Fakultas Ekonomi dan Bisnis, Universitas Putra Indonesia "YPTK" \\ ${ }^{2}$ Program Studi Manajemen, Sekolah Tinggi Ilmu Ekonomi Perdagangan \\ Email: 1eliza@upiyptk.ac.id, 2jumiatulmulya89@gmail.com
}

\begin{abstract}
ABSTRAK. SMA Negeri 2 Padang Panjang adalah peserta didik yang merupakan kelompok kecil dari masyarakat yang akan menghadapi dunia kerja untuk memenuhi kebutuhan fianasial mereka, saat ini pengerakan dunia industri sangat cepat, sehingga para peserta didik tersebut harus mampu mengikuti perkembangan zaman dengan membekali diri menjadi sosok yang kreatif, inovatif, berpikir maju (tidak hanya untuk mencari lapangan pekerjaan saja, tetapi mampu menciptakan lapangan pekerjaan bagi orang) agar menjadi sosok yang mandiri dan tangguh menghadapi tantangan. Adapun tujuan dari edukasi kepada peserta didik untuk mengembangkan jiwa wirausaha sejak dini agar dapat mandiri dan tangguh menghadapi tantangan di masa depan yang mampu mengembangkan diri menjadi produktif, kreatif, inovatif sejak dini yang dimulai dari bagian kecil yaitu melalui media online dalam menghadapi situasi dan kondisi pandemi covid-19. Metode yang digunakan dalam kegiatan ini adalah sosialisasi, diskusi, serta tanya jawab tentang membangun jiwa wirausaha secara online tersebut secara virtual Zoom Cloud Meeting, mengingat situasi dan kondisi saat ini untuk mengurangi mobilitas dan menjaga segala sesuatunya agar tetap aman pada semua pihak yang terkait dalam kegiatan ini. Dengan adanya sosialisasi ini diharapkan peserta didik yang mengikuti kegiatan ini sejak dini mampu mengembangkan diri untuk menjadi sosok entrepreneurship dalam menciptakan sesuatu sesuai dengan skill yang dimiliki untuk menghadapi tantangan masa depan yang semakin pesat dan persaingan ketat pada revolution industry 4.0 dan era society 5.0.
\end{abstract}

Kata Kunci: Peserta Didik; Jiwa Wirausaha; Media Online; Pandemi

ABSTRACT. SMA Negeri 2 Padang Panjang are students who are a small group of people who will face the world of work to meet their financial needs, currently the industrial world is moving very fast, so these students must be able to keep up with the times by equipping themselves to be creative figures., innovative, think ahead (not only to find jobs, but able to create jobs for people) in order to become an independent and resilient figure in facing challenges. The purpose of education for students is to develop an entrepreneurial spirit from an early age so that they can be independent and resilient in facing future challenges that are able to develop themselves to be productive, creative, innovative from an early age starting from a small part, namely through online media in dealing with pandemic situations and conditions. covid-19. The methods used in this activity are socialization, discussion, and questions and answers about building the entrepreneurial spirit online by virtual Zoom Cloud Meeting, considering the current situation and conditions to reduce mobility and keep things safe for all parties involved in the activity. this. With this socialization, it is hoped that students who take part in this activity from an early age will be able to develop themselves to become entrepreneurial figures in creating something according to their skills to face the increasingly rapid future challenges and fierce competition in industrial revolution 4.0 and society 5.0 era.

Keywords: Students; Entrepreneurial Spirit; Online Media; Pandemic

\section{PENDAHULUAN}

Ilmu pengetahuan dan teknologi kian hari makin berkembang sangat pesat, apalagi tingkat pertumbuhan pembangunan dan industri telah melewati masa pembaharuan di era serba digital. Era yang serba digital ini banyak sekali bentuk kemudahan dalam segala bidang, namun hal tersebut membuat peran tenaga kerja manusia semakin rendah karena secara tidak langsung SDM sudah digantikan dengan mesin dan teknologi. Lebih lanjut, dalam hal ini pembahasan wirausaha menurut Joshep Schumpeter dalam Alma Buchari (2008) bahwa wirausaha adalah orang yang mendobrak sistem ekonomi yang ada dengan memperkenalkan barang dan jasa yang baru, dengan menciptakan bentuk organisasi baru atau mengolah bahan baku baru.
Menurut Rinaldy dan Yosi (2021) Pertumbuhan ekonomi Kota Padang tahun 2020 mengalami perlambatan cukup signifikan sebesar $-1,86 \%$ jika dibandingkan dengan 5,65\% (2019), meskipun perlambatan ini masih jauh dibawah rata-rata nasional dan Provinsi Sumatera Barat (menurut perkiraan sementara). Terdapat 8 sektor yang mengalami penurunan nilai berdasarkan data PDRB Kota Padang tahun 2020, yaitu: sektor pertambangan dan penggalian, sektor pengadaan listrik dan gas, sektor konstruksi, sektor perdagangan besar dan eceran, reparasi mobil dan sepeda motor, sektor transportasi dan pergudangan, sektor penyediaan akomodasi dan makan/minum, sektor jasa perusahaan, dan sektor jasa lainnya. Sektor penyediaan akomodasi dan makan minum, mengalami penurunan dari Rp. 935,09 M (2019) menjadi Rp. 745,82 M (2020), atau 
Dharmakarya: Jurnal Aplikasi Ipteks untuk Masyarakat
ISSN 1410 - 5675 eISSN $2614-2392$

\section{Prosedur Kerja}

Dalam pelaksanaan kegiatan, metode dan Salah satu kota yang ada di daerah Sumatera Barat adalah Padang Pariaman. Menurut Langgam. id (2020) Pemerintah Kota Padang Panjang terus meningkatkan kualitas jaringan internet. Hal in dilakukan untuk mendorong peningkatan transaks digital oleh masyarakat dan pedagang. "Para pebisnis makanan tentunya akan sangat terbantu dengan pemesanan secara pemesanan secara daing mat terbatasnya

Media Online adalah sebuah sarana untuk berkomunikasi secara online melalui website dan aplikasi yang hanya bisa diakses dengan internet Berisikan teks, suara, foto dan video. Pengertia media online secara umum mencakupi semua jenis situs website dan aplikasi, termasuk situs berita, situs perusahaan, situs lembaga/instansi, blog, forum komunitas, media sosial situs jualan (e-commerce online store) dan aplikasi chattingan (Romli, 2012)

Pengembangan jiwa wirausaha harus dilakukan mulai dari hal yang kecil, yaitu melalui peserta didik, dengan lingkup kecil adalah sekolah melalui media online untuk membentuk pola pikir peserta didk tersebut, mengasah mestif menciptakan sesuatu yang baru se

Menghadapi hal tersebut tentu perluny pemberian pemahaman kepada generasi muda khususnya kepada para peserta didik setara SMA, untuk menjadi pribadi yang inovatif dan kreatif sejak dini agar mereka bisa mandiri secara finansial untuk memenuhi kebutuhan hidupnya. Salah satu bentuk dari jiwa yang produktif adalah merubah pandangan dan pola pikir untuk menjadikan dir sendiri sebagai pribadi yang mandiri dan tangoul dan siap menghadapi tantangan di masa pendemid masa depan Di ra yang cangih dan pecker teknologi dan industri yang telah memonga 4.0 dn juga era 4.0 dan jug ina socicty 5.0 hendaknya mampu menciptakan lapangan pekejaan sendir dengan inovatif, kreatifas yang dimiliki, sehingga tidak hanya memberikan manfaat untuk diri sendiri, tetapi untuk banyak orang.

Mengingat pentingnya pemahaman untuk dapat mengembangkan jiwa inovatif dan kreatif sajak din kepada para peserta didik SMA agar mereka dapat mandiri secara finansial, maka kami dari tim PKM UPI YPTK Padang akan memberikan pembinaan dan edukasi kepada para peserta didik tersebut, begitu pentingnya untuk membangun jiwa inovatif dan kreatif sejak dini dan di era serba digital ini, seuai dengan perkembangan zamannya.

Disini kami dari tim PKM akan mencoba berbagi ilmu dan pengalaman kepada para peserta didik dan memberikan pemahaman tentang jiwa wirausaha yang di mulai dari lingkungan sekolah melalui koperasi siswa agar mereka mengembangka potensi diri yang mereka miliki. Memiliki jiwa wirausaha yang inovatif dan kreatif artinya segala sesuatu akan nampak seperti peluang usaha dan membuka lapangan pekerjaan tidak hanya bag dirinya sendiri, namun juga bagi orang lain, sehingg memberikan manfat yang besar tidak hanya bagi memberik Oleh karen inyak orang.

Oleh karena itu dengan memperhatikan permasalahan yang terjadi di masyarakat, serta minim miliki, dan memberikan pembelajaran yang berarti, bagaimana mampu membuka lapangan pekerjaan sendiri, bukan hanya selalu berpikir hanya mencar perkerjaan bagi kalangan remaja khususnya peserta didik SMA, maka kami dari Tim PKM UPI YPTK Padang melakukan kegiatan ini di sekolah SMA Negeri 2 Padang Panjang, semoga kelompok kecil dari masyarakat ini bisa mengikuti perubahan teknologi di era revolusi industri dan era society dengan cermat dan bijak.

Sebelumnya kegiatan ini juga pernah dilakukan pelatihan kewirausahaan melalui pendanaan DRPM Direktorat Jenderal Riset dan Pengembangan KEMENRISTEKDIKTI Skema Program Kemitraa Masyarakat Stimulus (PKMS) tahun 2019 dan telah dipublikasi melalui URL http://jurnal.unpad.ac.id/ dharmakarya/article/view/24118/12137, begitu juga video kegiatan dari PKMS tersebut yang telah memiliki Hak Kekayaan Intelektual dengan nomo pencatatan HAKI 000209937.

\section{METODE}

Metode pelaksanaan kegiatan ini adalah secara virtual melalui online dengan menggunakan platform Zoom Cloud Meeting, penggunaan internet secara umum, dan pemanfaatan WhatsApp.

Pembelajaran Jarak Jauh akan dilaksanakan di tempat masing-masing dengan menggunaka sarana virtual aplikasi Zoom Cloud Meeting.

\section{Lingkup Pelaksanaan}

1. Menyediakan materi tentang kegiatan yang akan digunakan bagi peserta kegiatan sosialisasi dan edukasi.

2. Memberikan pemberdayaan tentang kepada peserta didik agar mampu menjadi pribadi yang bermanfaat bagi lingkungannya, imajinatif, dan inovatif bertangeng jawab dan responsif dala inovatif, bertanggung jawab dan responsif dalam
berhubungan dengan orang lain.

3. Mengajukan proposal kegiatan sebagai bahan dasar pelaksanaan kegiatan, serta acuan untuk
mensukseskan kegiatan sosialisasi dan edukasi. berikut: BM UPI YPTK Padang dalam waktu yang terukur dan konsisten.

2. Memberikan pembelajaran tentang bagaimana

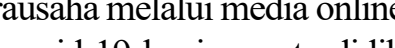
pada masa pandidi SMANegeri 2 Padang Panjang.

Me langsung tempat atau lokasi kegiatan. Kegitan ini diakhiri dengan membuat kerjasama berupa pengagendaan dan jadwal PKM-BM.

4. Mendata dengan baik seluruh peserta kegiatan dan fasilitas yang dapat digunaan selama kegiatan.

5. Merealisasikan seluruh agenda yang telah direncanakan secara tertulis dalam naskah proposal kegiatan PKM-BM. Kemudian menyerahkan kepada LPPM UPI YPTK Padang sesuai dengan arahan prosedur yang telah ditentukan.

\section{METODE}

Kegiatan pengabdian kepada masyarakat ini dilakukan dengan cara membagi informasi dengan cara mensosialisasikan kepada peserta didik dalam membangun jiwa wirausaha sejak dini melalui media online agar dapat mandiri secara finansial pada masa pandemi covid-19. Berikut implementasi kegiatan yang dapat diuraikan:

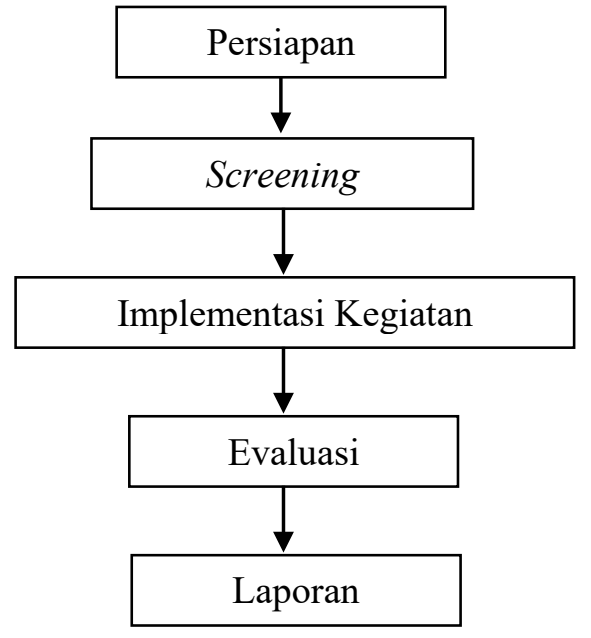

Gambar. 1 Diagram Proses Implementasi Kegiata

1. Persiapan

Persiapan dari kegiatan ini mencakup beberapa prosedur:

a. Menyiapkan materi

b. Survei lokasi

c. Mengurus surat-surat perizinan

d. Membuat proposal dan proses persetujuan lokasi pengabdian kepada masyarakat.
1. Melakukan rapat koordinasi bersama Tim PKMmembangun jiw wirusah melalu mediz olise
Screening

Setelah memaksimalkan persiapan, screening kemudian menjadi agenda selanjutnya. Ada beberapa tahap yang dilakukan:

a. Menyiapkan pembicara dan panitia sebelum acara

b. Memastikan semua alat-alat siap dibawa ke lokasi

Memastikan semua kebutuhan acara seperti transportasi dan spanduk

\section{Implementasi Kegiatan}

Tindakan atau pelaksanaan dari rencana yang sudah disusun dalam sosialisai dan edukasi yang diberikan kepada peserta didik di SMA Negeri 2 Padang Panjang, diantaranya:

a. Pemberian materi mengenai jiwa wirausaha kepada peserta didik di SMA Negeri 2 Padang Panjang.

b. Pemberian materi mengenai pemanfaatan media online untuk menumbuhkembangkan jiwa wirausaha kepada peserta didik di SMA Negeri 2 Padang Panjang.

4. Evaluasi

a. Semua anggota PKM diharapkan hadir

. Pelaksananya seluruh kegiatan sosialisasi dengan lancar dan sukses.

85\% semua anggota PKM harus memahami tentang jiwa wirausaha dan media online.

\section{Laporan Kegiatan}

Untuk mencapai tujuan yang akan diinginkan, maka dalam realisasi program tersebut diharapakan mitra dapat berpartisipasi dengan kegiatan, sebaga berikut:

a. Menjadi peserta sosialisasi, menerima teori, konsep, diskusi tanya jawab, serta hal-hal lain yang diberikan selama proses kegiatan berlangsung.

b. Menyediakan tempat dan fasilitas yang dibutuhkan selama proses kegiatan berlangsung.

\section{HASIL DAN PEMBAHASAN}

Kegiatan ini dilaksanakan dengan kolaborasi antara peserta didik (SMA Negeri 2 Padang Panjang) dengan tim pelaksana yang lansung menjadi pemateri yang telah dilaksanakan di SMA Negeri 2 Padang Panjang pada Bulan Desember 2020 - Januari 2021 berjalan lancar dan sukses sesuai target dan luara yang ingin dicapai dari kegiatan pengabdian kepada masyarakat ini.

Pengabdian Kepada Masyarakat di sekolah ini sangat bermanfaat khususnya bagi peserta didik SMA Negeri 2 Padang Panjang untuk membekali diri dari sekarang agar mampu menghadapi 
setiap tantangan yang ada di masa depan, apalagi saat ini kita sudah dalam era revolusi industry 4.0 dan era society 5.0 yang memang harus dihadapi, sehingga pada saat peserta didik tersebut sudah menamatkan sekolah, tidak fokus hanya pada mencari pekerjaan, tetapi bagaimana bisa menciptakan lapangan pekerjaan sendiri dengan memulai dari hal yang paling kecil.

Kegiatan ini membuat para peserta didik sangat antusias mengikutinya, terdapat dari para peserta didik tersebut mengajukan pertanyaan tentang bagaimana membangun jiwa usaha sejak dini, bagaimana memotivasi diri, bagaimana meman-faatkan media online dalam berwirausaha, dan masih banyak pertanyaan lainnya yang mereka ajukan sebagai sharing mereka dengan kegiatan ini dan juga tema yang memang cocok untuk mereka semua.

Berikut dapat dijabarkan beberapa hal yang telah dicapai dari kegiatan Pengabdian Kepada Masyarakat ini, diantaranya:

\section{Bagi Peserta Didik}

Kegiatan pengabdian kegiatan masyarakat ini bermanfaat bagi peserta didik dan juga orang tua dari peserta didik, dengan adanya sosialisasi dan edukasi ini dapat membuka mereka tentang dunia usaha yang dapat bertahan sekarang ini, yaitu adanya sebuah ide kreatif yang beda dengan lainnya yang sudah lebih dahulu tercipta oleh orang kebanyakan. Kegiatan ini akan membuka cakrawala berpikir peserta didik untuk menghadapi masa depan dengan tantangan yang tidak seperti mereka bayangkan saat ini, tetapi tantangan yang harus mampu mereka hadapi dan bagaimana mereka bijak dalam menghadapi tantangan tersebut dengan berpikir maju dalam menemukan peluangpeluang besar yang harus dikembangkan dalam mengatai berbagi tantangen tersebut sehingen mereka harus menyiapkan diri, membekli dir dengan kreatif, inovaif, tanggh, man dawn tang sosok, salah satunya mampu menciptakan lapangan
pekerjaan sendiri serta menjadi entrepreneurship pekerjaan sendiri
sukses dan handal.

\section{Bagi Tim Pelaksana Pengabdian}

Bagi kami para dosen pelaksana pengabdian kepada masyarakat, kegiatan sosialisasi dan edukasi ini merupakan salah satu kegiatan wajib dalam memenuhi Tridharma Perguruan Tinggi, yang mana tujuannya adalah dapat memberi manfaat bagi masyarakat banyak sesuai dengan bidang keilmuan yang kami miliki. Kegiatan pengabdian kepada masyarakat ini dapat berjalan lancer dan juga mendapat dukungan dari berbagai pihak.

Lebih lanjut, berikut ini merupakan dokumentasi dari kegiatan pengabdian beserta materi yang

diberikan kepada peserta didik SMA Negeri 2 Padang Panjang:

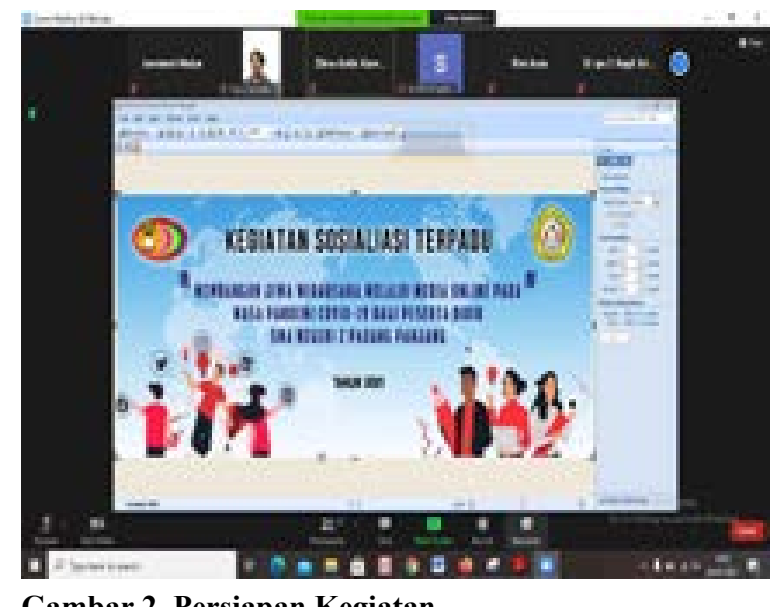

Gambar 2. Persiapan Kegiatan
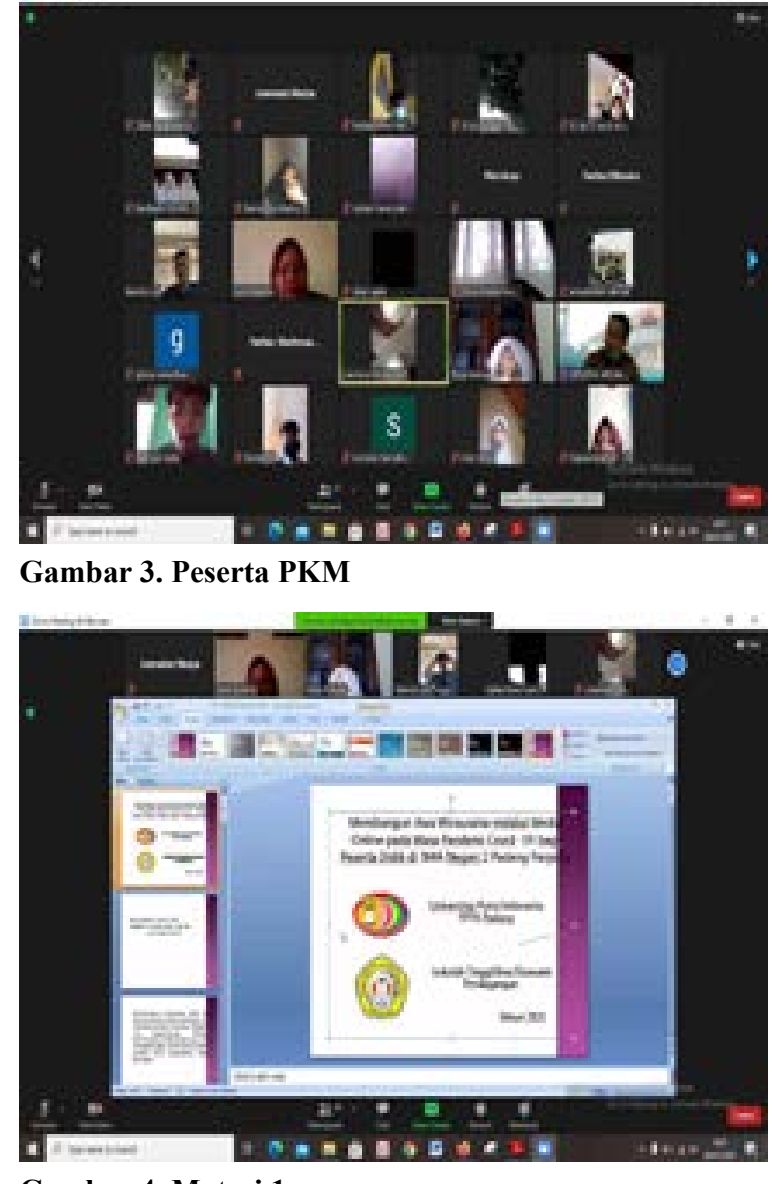

Gambar 4. Materi 1

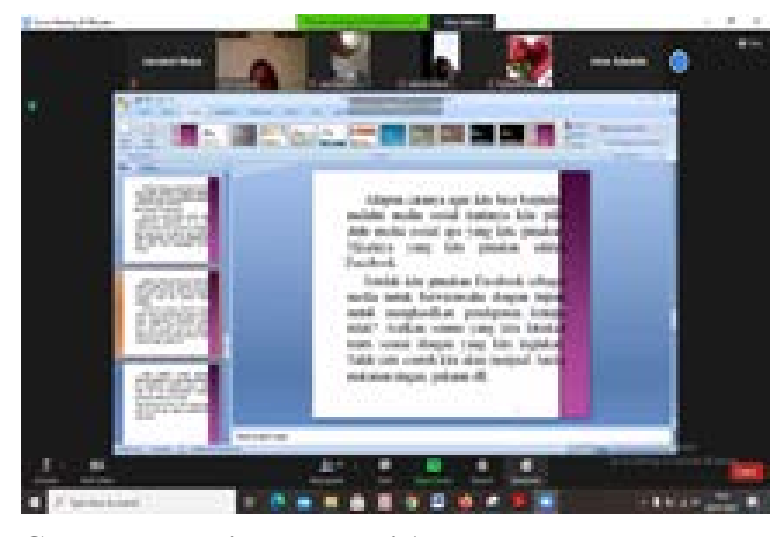

Gambar 5. Lanjutan Materi 1

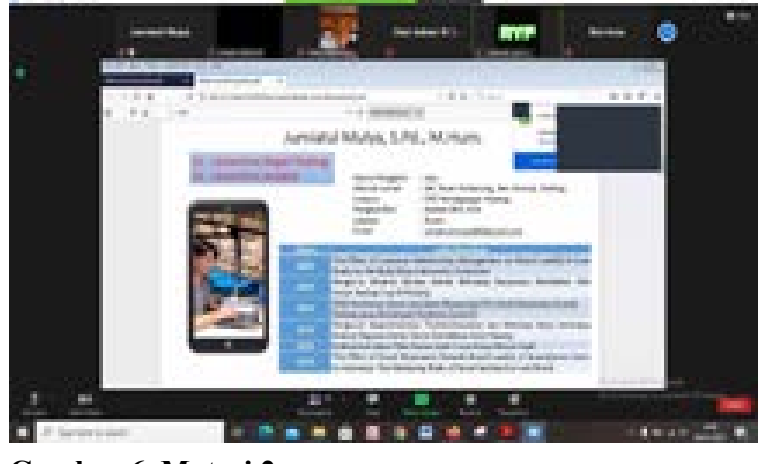

Gambar 6. Materi 2

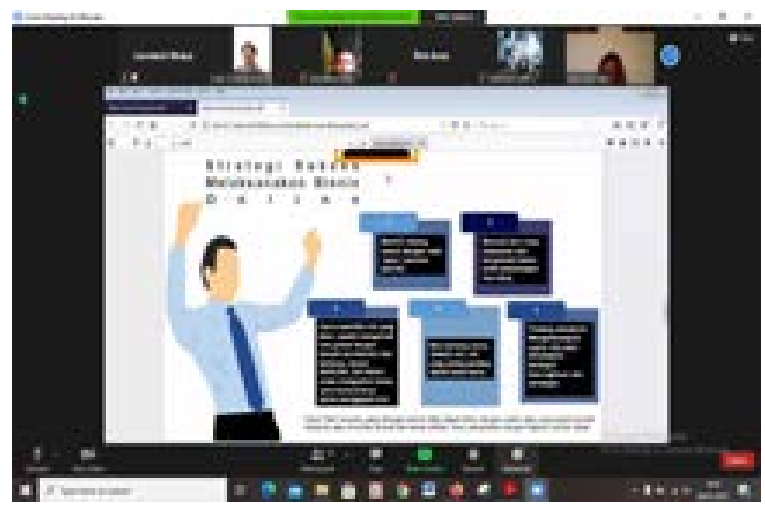

Gambar 7. Lanjutan Materi 2 SIMPULAN

Pelaksanaan kegiatan pengabdian jarak jauh secara Virtual merupakan salah satu cara untuk melakukan penyulusan kepada peserta didik SMA Negeri 2 Padang Panjang agar mereka termotivasi untuk melakukan bisnis secara online. Berdasarkan proses kegiatan yang telah dilakukan terhadap para peserta didik SMA Negeri 2 Padang Panjang para pesenting pentirausaha Covid-19 sejak Covid-19 sejak usia dini mendapatkan respon yang positif. Setelah diakukanya penyampaian materi, para peserta didik sangat antusias dengan memberikan pertanyaan-pertanyaan yang membu mereka ingin melakukan bisnis secara online. Dengan adanya sosialisasi dan edukasi tentang pentingnya Membangun Jiwa Wirausaha melalui Media Online pada Masa Pandemi Covid-19 sejak usia dini, khususnya terhadap para peserta didik SMA Negeri 2 Padang Panjang, maka diharapkan mampu membuka cakrawala berpikir peserta didik terhadap tantangan dunia kerja yang akan hadapi di masa yan antangan akan do dalam berion dalam rangka monghapi revolusi industry 4.0 dan era socity 5.0, sching sebuah kreatifitas yang unik dan bernilai guna, sehingga setelah mereka menyelesaikan studi mereka nantinya, tidak hanya menunggu mendapatkan pekerjaan, tetapi mampu membuka usaha sendiri dan kreatifitas yang mereka miliki.
UCAPAN TERIMAKASIH

Kegiatan Pengabdian Kepada Masyarakat Mandiri ini terlaksana, adanya kerjasama yang baik antara Universitas Putra Indonesia YPTK Padang dengan SMA Negeri 2 Padang Panjang. Kami selaku Tim Pelaksana Pengabdian Kepada Masyarakat Mandir mengucapkan kepada semua pihak yang telah memfasilitasi kegiatan ini. Harapan kedepannya semoga terus dapat berkerja sama Kembali pada kegiatan berbeda lainnya yang bermanfaat bag banyak orang.

\section{DAFTAR PUSTAKA}

Alma Buchari. 2008. Kewirausahaan, Edisi Revisi Bandung: Alfabeta.

Drucker, P.F. 1994. Innovation and Entrepreneurship, New York: Harpercollins Publisher.

Eliza, J. Mulya, N. Pratiwi, (2019). "Motivasi Bisnis melalui Kewirausahaan Gun Memberdayakan Koperasi Sekolah sebagai Sarana Berwirausaha bagi Peserta Didik SMA Negeri 2 Padang Panjang". Dharmakarya: Jurnal Aplikasi Ipteks untuk Masyarakat, Vol.8, No.4, Desember 2019; ISSN: 1410 5675, Hal: 227-230

M. Romli. 2012. Buku Jurnalistik Online: Panduan Mengelola Media Online. Bandung: Nuansa.

Rinaldy, Rudy dan Yosi Suryani . 2021. Performa Ekonomi Kota Padang Tahun 2020. https:// www.padang.go.id/performa-ekonomi-kotapadang-tahun-2020 di akses 24 Mei 2021.

Suryana.2003. Kewirausahaan Pedoman Praktis Kiat dan Proses Menuju Sukses (Edisi Revisi). Jakarta: Salemba Empat.

https://medium.com/@pendidikannasiona19 pengertian-koperasi-siswa-tujuan113b2a37100b, diunggah 05 Desember 2020 pukul 12.22 WIB.

http://akarkangkung.blogspot.com/2015/06 kewirausahaan-menurut-peter-f-drucker.html, diunggah 06 Desember 2020, pukul 17.20 WIB

https://www.akudigital.com/bisnis-tips/ pengertian-media-online/, diunggah 07 Dsember 2020, pukul 12.22 WIB.

https://id.wikipedia.org/wiki/Pandemi, diunggah 07 Dsember 2020, pukul 15.20 WIB 